\title{
8
}

\section{im

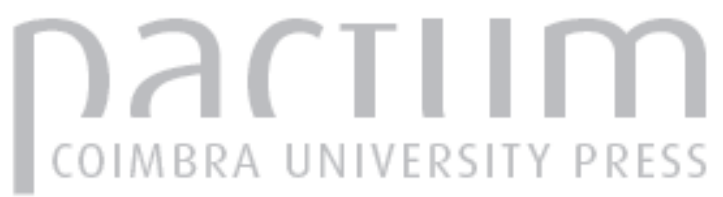

A correspondência inédita do embaixador de Portugal em Paris, D. Vicente de Sousa Coutinho

\author{
Autor(es): $\quad$ Matos, Manuel Cadafaz de
}

Publicado por: Imprensa da Universidade de Coimbra

URL persistente:

URI:http://hdl.handle.net/10316.2/43767

DOI:

DOI:https://doi.org/10.14195/2183-8925_10_8

Accessed : $\quad$ 26-Apr-2023 01:18:35

A navegação consulta e descarregamento dos títulos inseridos nas Bibliotecas Digitais UC Digitalis, UC Pombalina e UC Impactum, pressupõem a aceitação plena e sem reservas dos Termos e Condições de Uso destas Bibliotecas Digitais, disponíveis em https://digitalis.uc.pt/pt-pt/termos.

Conforme exposto nos referidos Termos e Condições de Uso, o descarregamento de títulos de acesso restrito requer uma licença válida de autorização devendo o utilizador aceder ao(s) documento(s) a partir de um endereço de IP da instituição detentora da supramencionada licença.

Ao utilizador é apenas permitido o descarregamento para uso pessoal, pelo que o emprego do(s) título(s) descarregado(s) para outro fim, designadamente comercial, carece de autorização do respetivo autor ou editor da obra.

Na medida em que todas as obras da UC Digitalis se encontram protegidas pelo Código do Direito de Autor e Direitos Conexos e demais legislação aplicável, toda a cópia, parcial ou total, deste documento, nos casos em que é legalmente admitida, deverá conter ou fazer-se acompanhar por este aviso.

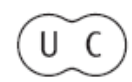


REVISTA DE HISTORIA DAS IDEIAS IO
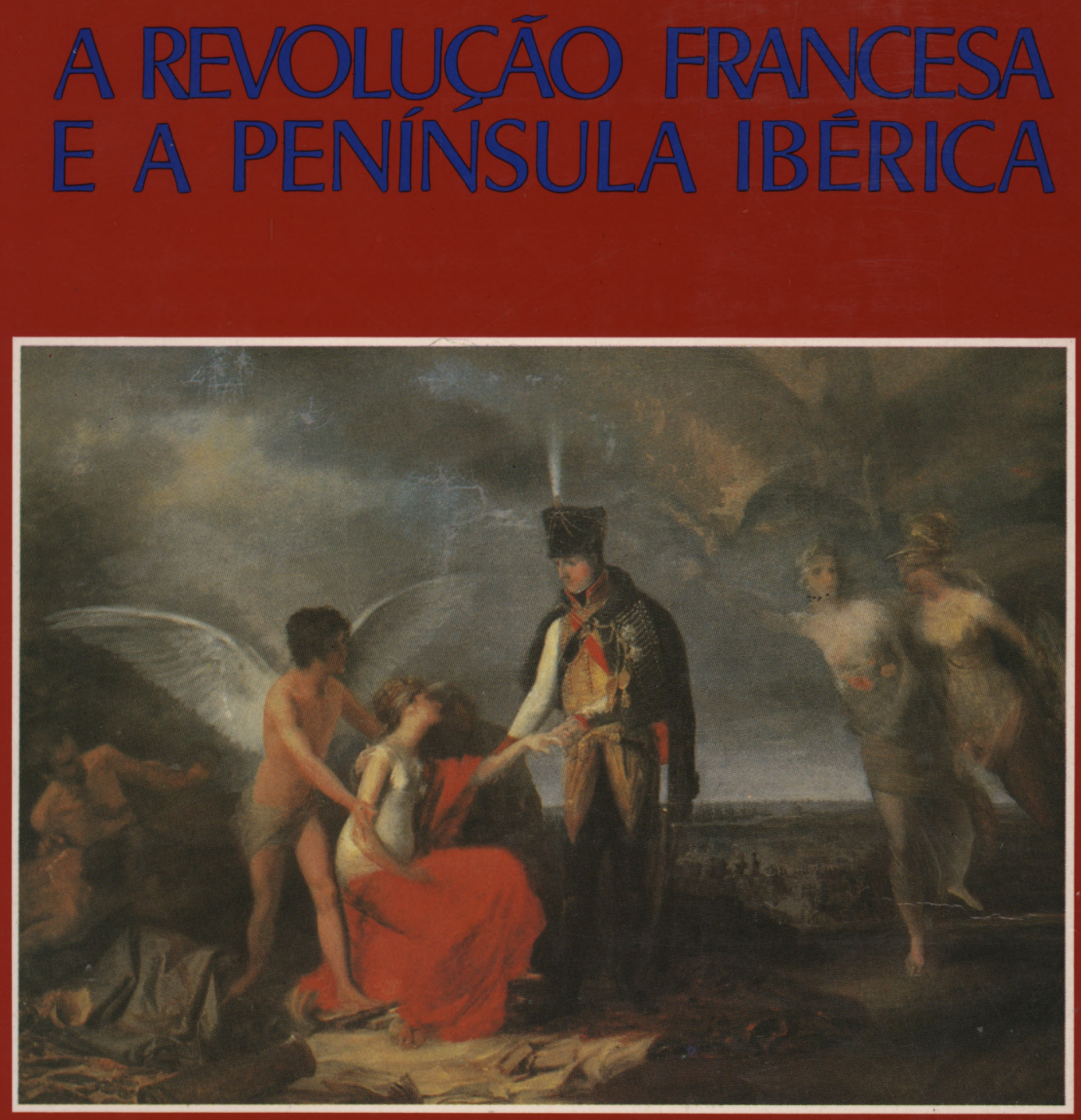

INSTITUTO DE HISTÖRIA E TEORIA DAS IDEIAS FACULDADE DE LETRAS 


\section{A CORRESPONDENCIA INÉDITA DO EMBAIXADOR DE PORTUGAL EM PARIS, D. VICENTE DE SOUSA COUTINHO}

No momento em que se verifica, em Julho de 1789, a grande eclosão da revolução, é embaixador de Portugal junto da corte francesa D. Vicente de Sousa Coutinho. O seu nome, aliás, já se encontrava há largo tempo associado à nossa representação diplomática naquele país.

Assim, datam já de 8 de Abril de 1763, segundo Fernando de Castro Brandão $\left({ }^{1}\right)$, as «cartas credenciais» para aquele diplomata, «na qualidade de ministro plenipotenciário junto de Luís XV». É cerca de uma década depois, no entanto, mais precisamente em 10 de Março de 1771, que a corte portuguesa faz remeter para Paris, segundo aquele mesmo autor, as «cartas credenciais» em favor de D. Vicente de Sousa Coutinho como Ministro do reino.

Entretanto, quase dois anos depois, em 1 de Março de 1774, um outro Sousa Coutinho, D. Luís Pinto de S. C., 1. ${ }^{\circ}$ visconde de Balsemão e $20 .^{\circ}$ senhor do morgadio do mesmo nome, é nomeado, por sua vez, ministro plenipotenciário português na corte de Londres. $\mathrm{E}$ ao voltar ao nosso país em gozo de uma licença, cerca de uma década e meia depois, ou seja em meados de Dezembro de 1788, este visconde de Balsemão é surpreendido com a sua nomeação, ainda que interinamente $\left({ }^{2}\right)$, para titular da secretaria de Estado dos Negócios Estrangeiros $\left(^{3}\right)$.

* Antropólogo. Mestrando no Departamento de Estudos Portug!reses da UNL.

(1) Fernando de Castro Brandão, Sinopse Cronológica da História Diploinática Portuguesa, Biblioteca Diplomática, série A, Lisboa, Ministério dos Negócios Estrangeiros, 1984, p. 65.

(2) F.C. Brandão, ob. cit., p. 68.

(3) A Lusitânia, Revista de Estudos Portugueses, superiormente dirigida por Carolina Michaëlis de Vasconcelos, apresenta-nos, no seu 
É essencialmente a partir dessa altura que ganha foros de grande importância a correspondência que lhe é dirigida de Paris por aquele embaixador português, com funções plenipotenciárias junto da corte francesa, D. Vicente de Sousa Coutinho. Tal epistolografia, que só cessará com a morte daquele em Maio de 1792, torna-se, assim, particularmente rica quando, a partir de Abril-Maio de 1789, nos dá um relato dos principais factos que levam à eclosão da revolução de Julho desse ano e dos tumultos (e demais acontecimentos) que se lhe seguiram.

Esta correspondência motivou até há pouco tempo, uma certa apatia (ou mesmo desconhecimento) por parte da comunidade de investigadores mais preocupados com o período setecentista português, mantendo-se ainda hoje, na sua esmagadora maioria, inédita.

Tal espólio, aliás, manteve-se até há não muitos anos, nos arquivos do Ministério dos Negócios Estrangeiros, em Lisboa, após o que transitou para o Arquivo Nacional da Torre do Tombo. Entre os investigadores que, num tempo decerto mais remoto, se debruçaram sobre este espólio, encontram-se Latino Coelho (29.11.1825 - 29.8.1891) e Luz Soriano (8.9.1802 - 18.8. 1891) $\left({ }^{4}\right)$. O primeiro daqueles historiadores $\left({ }^{5}\right)$ abordou sumariamente, com efeito, o conteúdo de tal espólio, na sua representativa obra História Política e Militar de Portugal desde os Fins do Século XVIII até 1814 (em três volumes). Quanto ao segundo autor, ou seja, Luz Soriano, também não foi muito longe na leitura desse mesmo espólio pela análise que dele faz na sua História da Guerra Civil e do Estabelecimento do Go-

vol. III (Fasc. VIII, de Dezembro de 1925, p. 210), a reprodução de uma estanıpa com a indicação de ser o retrato de D. Domingos de Sousa Coutinho. Ernesto Soares, no entanto in Francisco Bartolozzi e os seus Discípulos em Portugal, Gaia, Edições Apolino, 1930, nt. 41, 2, regista que "houve evidente confusão que facilmente se desfaz, observando idêntico retrato, aberto pelo gravador Manuel Marques de Aguilar, onde vem bem expresso o nome de Luís Pinto de Sousa Covtinho, Visconde de Balsemão. No retrato por Aguilar vê-se a mais a condecoração do Tosão d'Ouro e é datada de 1801 ". Este mesmo retrato é ainda patente in Ernesto Soares, Dicionário de Iconografia Portuguesa (Retratos de Portugueses e Estrangeiros em Relacões com Portugal), Lisboa, Instituto d $\epsilon$ Alta Cultura, vol. 3, 1950, pp. 370-371.

(4) Devemos esta informação à Dr.a Ana Cristina Araújo IUniversidade de Coimbra).

(5) Interessa também a este período aqui abordado um outro estudo de Latino Coelho. Trata-se do "Elogio de José Bonifácio de Andrade Silva", publicado nas Memórias da Academia de Ciências de Lisboa. Essa destacada figura, prestimoso químico e orador, acompanlıou de perto, em Paris, uma significativa parte da Revolução, enquanto ali estudava com grandes mestres, como Lavoisier. 
verno Parlamentar em Portugal (obra publicada, em 17 volumes, entre 1866 e 1884).

$\mathrm{O}$ autor que levou mais longe o seu estudo sobre essa correspondência remetida de Paris por D. Vicente de Sousa Coutinho para o $1 .^{\circ}$ visconde de Balsemão foi efectivamente Caetano Beirão (5.11.1892 - 21.1.1968), designadamente através da sua obra $D$. Maria I - 1777-1792 - Subsídios para a Revisão da História do Seu Reinado, inicialmente publicada em 1934. Tendo nós ainda tido o grato privilégio de conhecer pessoalmente esse grande advogado e historiador na segunda metade da década de sessenta $\left(^{8}\right)$, cedo tivemos oportunidade de acompanhar o teor dessa obra fundamental $\left({ }^{7}\right)$. Não escondia, com efeito, Caetano Beirão, que «esta correspondência de D. Vicente de Sousa Coutinho merecia ser publicada na íntegra» $\left({ }^{8}\right)$.

E se outro fermento Caetano Beirão não deixasse em nós a tal respeito, o mais decisivo foi, seguramente, o de contribuirmos, com o nosso modesto esforço, para que tal espólio fosse conhecido nas suas multifacetadas implicações, tanto num domínio social, cultural, como político. Este nosso labor, no que respeita à leitura de toda uma vasta epistolografia que só cessa com a morte daquele diplomata em Paris - em 8 de Maio de $1792\left({ }^{9}\right)$ - tendo sido iniciado em Dezembro de 1979, ainda se encontra, pela nossa parte, em vias de conclusão. De um particular incentivo veio a beneficiar, no entanto, este nosso projecto, quando em 1985 o Institut d'Histoire de la Révolution Française, por intermédio do seu secretário-geral, prof. Michel

(6) Conhecemo-lo quando, ainda estudante de Direito e na qualidade de assessor dos advogados Jaime do Rego Afreixo e Mário Pais de Sousa, estes dois notáveis "tribunos» mantinham com aquele amigáveis relações que iam muito além da camaradagem imposta além das barras dos tribunais.

(7) Logo após ter sido publicada em 1934 a primeira edição de D. Maria, o Estado Português, por intermédio do Secretariado de Propaganda Nacional, galardoou tal obra com o prémio "Alexandre Herculano».

(8) Caetano Beirão, D. Maria I-subsídios para a revisão da izistória do seu reinado, Lisboa, Empresa Nacional de Publicidade, 3.a edição, com novos aditamentos, 1944, p. 382.

(9) Tal epistolografia, em termos quantitativos, poder-se-á assim eq:acionar (não nos referimos ao material existente anterior a essa data): 75 cartas desde o mês de Abril de 1789 até ao fim desse ano; 124 cartas desde 1 de Janeiro de 1790 até 31 de Dezembro (do mesmo ano); 158 cartas desde 3 de Janeiro de 1791 até 28 de Novembro (desse ano), e 54 cartas desde 3 de Janeiro de 1792 até 4 de Maio de 1792; datando a última carta desse diplomata em quatro dias antes da sua morte. Esta parte do espólio perfaz, assim, um total de 411 cartas. 
Vovelle, se interessou pela sua oportuna publicação, designadamente em Paris.

Um grande repositório de dados de notória incidência sociológica e antropológica

Nestes anos que temos dedicado ao estudo da epistolografia diplomática de D. Vicente de Sousa Coutinho - particularmente ao cerca de meio milhar de documentos que constitui o cerne do seu espólio de 1789 a 1792 - , uma particularidade se nos afigura por demais notória. É o facto de ela nos apresentar um grande repositório de dados de notória incidência sociológica e antropológica.

Através destas numerosas cartas (e o nosso embaixador escreve várias por semana), podemos reconstituir como que o diário da Revolução vista por um estrangeiro. Em muitos dos casos - e sobretudo na primeira fase da sua descrição dos acontecimentos de 1789 - a sua leitura é, se não imparcial, pelo menos factualmente objectiva.

Só que, em breve, dessa leitura objectiva dos factos o próprio diplomata português em Paris passa a assumir de bom grado (mesmo que em parte procurasse dissimular nos seus escritos) o fervor patriótico da própria Revolução. $O$ governo português, aliás, ao que revela Caetano Beirão $\left({ }^{10}\right)$, não poderia obstar a «que assim se procedesse, quando o(s) próprio(s) secretário(s) de Estado se mostrava(m) favorável(eis) à remodelação que tão violentamente se estava a operar em França (?)». A Rainha D. Maria I, com efeito, mostrava uma grande vontade de acompanhar tudo o que se ia passando naquele país. Daí que D. Luís de Sousa Coutinho, 1. $0^{\circ}$ visconde de Balsemão e (já então) ministro dos Negócios Estrangeiros e da Guerra, instasse junto do nosso diplomata credenciado em Versailles para que (nos) relatasse a par e passo o que de mais significativo já se ia desenrolando.

\section{Antes da tomada da Bastilha}

Já depois de Maio de 1789, D. Vicente de Sousa Coutinho vai descrevendo - num tom que, nos primeiros tempos, vai a pouco e pouco denunciando a sua adesão aos ideais da pré-

(10) Caetano Beirão, ob. cit., p. 381. 


\section{Embaixador de Portugal em Paris}

-Revolução - todos os principais eventos registados na capital francesa, de natureza política e não só. Assim, reportando-se ao julgamento das ordens superiores no Terceiro Estado ${ }^{11}$ ), aquele diplomata português não deixa de manifestar a sua própria adesão e até mesmo o seu louvor aos acontecimentos. Refere ele a propósito: «Não faltou a este grande e venturoso espectáculo senão um maior número de espectadores.... França queria ser testemunha». E, após noticiar, no dia 24, que o duque de Orleães e mais 40 fidalgos se haviam agregado aos revoltosos, sublinhava em 30 de Junho: "Nesta cidade os fogos de artifício e iluminações e mais festejos têm chegado ao extremo a que o Povo leva tudo nos momentos de júbilo ou de tristeza».

Deste período podemos ainda hoje dispôr em Portugal de outras fontes documentais que nos reportam, a par e passo, ao evoluir de tais acontecimentos. As mais destacadas dessas fontes são, sem dúvida, a Gazeta de Lisboa e o. Jornal Encyclopédico, que à altura se publicavam na capital.

Também essas publicações, com efeito, procuravam noticiar tais eventos de uma forma calorosa e nem sempre isenta de uma certa e «bem intencionada» adesão aos ideais revolucionários, pelo menos no primeiro período.

A Gazeta de Lisboa, com efeito, dava circunstanciado eco de

"todos esses sucessos, num tom de optimismo que faz pensar se a corte portuguesa não estaria (pelo menos nos primeiros tempos) ao lado da Revolução... O duque de Orleães é constantemente apresentado como modelo dos príncipes, o amigo do povo, a honradez em pessoa que há-de regenerar a França. Reproduzem-se as suas instruções aos procuradores dos bailados, contem-se os seus actos de abnegação pelos humildes, ora salvando um criado da morte, ora mitigando a fome aos miseráveis; referem-se os aplausos delirantes com que o público o acolhe, na Opera, no Palais-Royal e nas ruas. Ao mesmo tempo, dá-se conhecimento dos discursos da Assembleia Nacional, das sedições por falta de trigo, da inquietação que reina por toda a parte e da desordem que vai alastrando...." (12).

Mas se em 30 de Junho de 1789 o povo de Paris - ciente de que a situação em breve iria mudar - dava vivas ao seu contentamento com múltiplos fogos de artifício e iluminações, cerca de duas semanas depois passava já do esperançado regozijo à própria aç̧ão. É assim que, em 12 de Julho, tem lugar na capital francesa uma série de seis importantes acontecimen-

(11) Idem, p. 385.

(12) Idem, ibidem. 
tos que Gérard Walter $\left({ }^{13}\right)$, no seu quadro cronológico da Revolução, equaciona nesta ordem:

- manifestação em honra de Necker

- encerramento da Bolsa

- apelo ao uso das armas, por Camille Desmoulins, no Palais-Royal

- a carga do príncipe de Lambesc, nas Tulherias

- incêndio em trincheiras

- pilhagens nocturnas

Esta série de tumultuosos acontecimentos vem, assim, ser como que a gota de água que leva o copo a transbordar e a Revolução, dois dias depois, a sair à rua (em massa) em 14 de Julho. Mas nesse dia 12 é ainda o nosso embaixador D. Vicente de Sousa Coutinho - que não pode, naturalmente, assistir impassível a tão significativas movimentações populares - que dá à corte portuguesa registos como este:

«Hontem (dia 12) pelas quatro horas da tarde chegou hũ homem ao jardim do Palais-Royal gritando: Estamos perdidos: iá não temos Pay! Despediram Mr. Nekcer: (14). Seguio-se logo hũ confuso alarido: As armas, As armas. E já corrião em bandos a buscá-las; quando hũ mais prudente lhes bradou: Que quereis com essas armas sem Chefe e sem destino?....».

Ao cair da noite a situação em Paris não era mais calma. E ainda D. Vicente de Sousa Coutinho que nos dá o testemunho - no seu despacho de 12 de Junho - de tais acontecimentos:

"A noite os Guardas franceses atiravão com balla a todos os soldados, que não herão do partido do povo, e hoje se

(13) Gérard Walter, XVIII Siécle - les événements. La Révolution Française, Paris, Éditions Albin Michel, Collection Le Memorial des Siècles, 1967, p. 82.

(14) Em termos de relato da crise que a França então vinha atravessando, é sintomática a descrição que D. Vicente de Sousa Coutinho fazia em 16 de Janeiro desse ano de 1789 (A.N.T.T. - M.E. - III - A-Fr. L. 15, n. 129 ): «....não há exemplo (de que) gosasse nenhũ homem debaxo do aspecto de tamanha crise. A navegação tem padecido infinito, não só nos portos do Norte, mas em outros.... (Marselha, Bordeus, e Cherburgo tem sido espectaculos tristes de numerosos navfrágios. Não obstante estes accidentes, desastres nas colónias, as interrupções do Comércio do Levante, he neste momento tal a fraqueza dos especuladores em França, que estão os armasens atulhados de mercadorias de todos os géneros sem extracção nem para dentro nem para fora do Reyno. Temse abaixado os preços porém nada é bastante para animar a industria enquanto não melhorar de situação esta monarchia». 
achavão já no Palais-Royal, perto de dez mil homens armados, a quem ensinavão o exercício. - Enfím, o dia de hontem foi hũ de calamidade».

Mas se após o despacho de Paris de D. Vicente de Sousa Coutinho - datado de 13 de Julho mas reportando-se aos acontecimentos da véspera - nada mais sabemos das suas impressões desses tumultuosos dias senão no dia 17 desse mesmo mês, tal já não se verifica em relação aos relatos da Gazeta de Lisboa sobre os mesmos acontecimentos.

Efectivamente, numa carta datada de Paris desse mesmo dia 13 de Julho, mas só publicada em Lisboa a 4 de Agosto $\left({ }^{15}\right)$, descreve-se, para lá do desterro (provisório) de Necker e da revolta dos soldados contra o príncipe de Lambesc, os comícios do Palais-Royal, o cortejo com o busto de Orleães, a libertação dos presos, o desarmamento da guarda pela plebe, os toques a rebate, os 300 mil cidadãos armados (a defesa da cidade está «entregue a cidadãos honrados e limpos»), a rebelião, enfim... $\left({ }^{16}\right)$. E em toda esta descrição, tal como aliás acontece

(15) Nesse seu mesmo despacho de 13 de Julho, o nosso embaixador referia ainda, mais adiante: «Mr. Necker recebeo sábado hũa carta de El Rey na qual lhe dizia ser conveniente retirar-se do serviço para se adquirir o socego que estava perdido. Elle partio imediatamente, e neste instante se achará já fora do Reyno». Efectivamente, a Côrte, acusando Necker de ter desencadeado a Revolução, tinha acabado por o destituir do seu cargo de ministro de Estado em 11 de Julho. Foi essa medida que, em grande parte, levou não só ao encerramento da Bolsa, como fez eclodir imenso furor popular que, dias depois, levou à tomada da Bastilha em 14 de Julho. A sua chamada pelos revoltosos ao reassumir as suas funções, em 16 de Julho, seria mais que um triunfo pessoal, uma vitória sobre a monarquia. Ele manter-se-á assim em funções até Setembro de 1790 e em breve conhecerá, com sua filha, Mme. de Staël, o amargo caminho do exílio. É durante o seu exílio em Roma que, então, a vida desta dama se cruza com a de um português, D. Pedro de Sousa Holstein, futuro duque de Palmela. Vide, a propósito, o capítulo "Os Amores Portugueses de Madame de Staël» in Vitorino Nemésio, Relações Francesas do Romantismo Português, Coimbra, 1936.

Mme. de Staël - ao que refere, por sua vez, Jacinto do Prado Coelho, tradutor e prefaciador (e autor das notas) da obra Literatura Francesa, colecção História Ilustrada das Grandes Literaturas, Estúdios Cor, Lisboa, 1955, p. 257 - «conhecia bem a obra de Camões». Veja-se por sua vez a esse respeito, Condessa Jean de Pange, "Madame de Staël e Camões", Revue de Littérature Comparée, Julho-Setembro de 1939, pp. 361-368. Com efeito, «em 1806, para manter a seu lado o homem que amava, chegou a propor-lhe que empreendessem, em comum, uma tradução dos Lusíadas em versos franceses".

(16) Este relato só foi publicado na Gazeta de Lisboa nesse dia de Agosto, devido ao isolamento que sentiu Paris logo após a tomada da Bastilha. 
nas do diplomata português credenciado em Versailles, as opiniões estão longe de apoiar a situação agonizante da Monarquia.

Esse número da Gazeta de Lisboa dos começos de Agosto de 1789, encerra, curiosamente, com uma nota deveras sintomática:

«Como a famosa Revolução de Paris he o mais interessante objecto da presente conjunctura, e desejamos que os nossos leitores saibão verdadeiramente as suas ulteriores circunstâncias (que huma voz mal fundada exaggera sobremaneira) publicaremos amanhã em hũ Suplemento extraórdinário huma carta fidedigna, que, em data de 17 de Julho, acabamos de receber daquela capital a este respeito».

Entretanto a tomada da Bastilha, peça fulcral da engrenagem de toda a rebelião popular parisiense desse período, é relatada em cima do(s) acontecimentos(s) pelo correspondente da Gazeta de Lisboa em Paris. Enquanto a 14, 15 e 16 de Julho (de 1789) aquele correspondente acompanha, pela sua crónica, os vários aspectos da evolução dos acontecimentos, o embaixador português D. Vicente de Sousa Coutinho deixa-se arrastar (e enredar, talvez) pelos acontecimentos e só procura enviar para a corte em Lisboa o seu despacho, no dia $20\left({ }^{17}\right)$, cerca de uma semana depois da tomada daquela fortaleza $\left({ }^{18}\right)$.

(17) Isso não obsta a que, em 17 de Julho, aquele diplomata tenha feito seguir para Lisboa uma curta missiva, não excedendo uma dezena de linhas, em que afirma, designadamente: «Não sabendo se o correio está livre, não posso escrever o que se passa; mas dentro de mais três dias, V. Ex." receberá a relação de um sucesso de que não há exemplo na história do mundo. El-Rei veio à caza da Camara desta cidade, sem algumas guardas hoje, e somente acompanhado do Povo. Todos os novos Ministros sahirão, e forão chamados os precedentes (M.E.-III - A, Fr. C., $15, \mathrm{n} \cdot{ }^{\circ} 200$ ).

(18) Já depois da apresentação desta comunicação e da organização do volume (sob a nossa responsabilidade) intitulado $O$ dia $a$ dia da Revolução Francesa nas impressões do embaixador de Portugal em Paris, D. Vicente de Sousa Coutinho, no prelo, tivemos conhecimento do trabalho de Maria Áquila Neves dos Santos, Pré-Revolução em França, 1788-1789 - A óptica do Embaixador Sousa Coutinho, Coimbra, 1970. 